\title{
What Geriatrics Know about Specific Medications
}

\author{
Mekdad Sanaa $\mathrm{S}^{1}$, Alsayed Adher $\mathrm{D}^{2}$ \& Alsayed Alaa $\mathrm{A}^{3}$ \\ ${ }^{1}$ Senior and Clinical Pharmacist King Fahad Medical City, Department of Pharmacy, KFMC, Riyadh 11525, \\ Saudi Arabia \\ ${ }^{2}$ Consultant Medical Oncology, King Faisal Hospital and Research Center, Oncology Center, King Faisal Hospital \\ and Research Center, Riyadh , 11211, Saudi Arabia \\ ${ }^{3}$ Medical student, King Saud Bin Abdulaziz University For Heath Sciences, Saudi Arabia \\ Correspondence: Sanaa Saeed Mekdad, Makkah Al Mukarramah Branch Rd, As Sulimaniyah, Riyadh 11525, \\ Saudi Arabia. Tel: 96-650-089-4048.
}

Received: June 4, 2017 Accepted: July 13, 2017 Online Published: July 14, 2017

doi:10.5539/gjhs.v9n9p97

URL: https://doi.org/10.5539/gjhs.v9n9p97

\begin{abstract}
The study has aimed to investigate the Medication Knowledge (MK) in elders and identify factors that affect knowledge and the areas that are needed to be enhanced. Moreover, the perception of elders in regards to knowledge provided by healthcare professionals (HCPs) has also been studied. A cross-sectional survey has been performed, which is comprised of elders in ambulatory care settings. A questionnaire about Medication Knowledge Assessment (MKAQ) has been prepared for data collection. Illiteracy, polypharmacy, and multiple clinic follow-ups have been identified as significant factors contributing towards inadequate knowledge. The study revealed that significant number of elders are self-dependent in taking and managing their medicines despite of increased age and multiple medical problems. $73 \%$ of the elders were aware about the place to keep their medications and $82 \% \mathrm{knew}$ about the next date of refill. However, male patients were found to be well-aware about direction of use $(\mathrm{P}=0.04)$ and indications $(\mathrm{P}=0.03)$. Evidence-based approaches individualized to the needs of elders, which are obligatory to be developed for advancing MK. The impact of these interventions should be studied in future on improving knowledge.
\end{abstract}

Keywords: geriatrics, healthcare professionals, knowledge, medication, polypharmacy

\section{Introduction}

The population of elders is getting increased at a constant rate across the globe. By 2050, the aging population is expected to increase by three folds in United States (Wiener \& Tilly, 2002; Boffetta, et al. 2014). A normal aging seems to be associated with hearing impairment and cognitive decline (Wayne \& Johnsrude, 2015). In cognitive function, the elders are at an increased risk of the pathological cause of decline with increased risks of neuropsychiatric disorders, such as depression and cerebrovascular accidents (Swe et al., 2010). Elderly people are mostly observed to suffer from multiple medical conditions; therefore, polypharmacy is common in this age group (Maher et al., 2014). These factors were added to the burden of challenge, which enables elderly people to obtain and retain medication knowledge. Furthermore, the polypharmacy seems to be associated with decreased adherence. The patient related factors have been examined by World Health Organization (WHO) as one of the most fundamental aspects, which are associated with adherence besides socioeconomic factors, healthcare system, diseases, and therapy related factors (Wu et al., 2008).

\subsection{Aim of the study}

There are very limited studies, which have highlighted the Medication Knowledge and its impact on elderly people. Hence, the enhancement of medication knowledge among elders is challenging and needs to be individualized. This study aimed to understand the knowledge of elders about their medication. Moreover, it examined the key areas of strengths and weaknesses in knowledge as well as to understand the way through which this knowledge can be utilized for a better medication management and improves the overall outcomes.

\section{Method}

A cross-sectional survey has been performed in an ambulatory care setting at a tertiary care center of King Fahd Medical City, Riyadh, Saudi Arabia from January to November 2014. 


\subsection{Participants}

The participants were comprised of elders, who were attending the outpatient pharmacy for prescriptions dispensing during the study period. The age of patients was 65 years and above. The total sample size of the study included 448 patients, with or without their caregivers. From the selected sample, 18 patients were excluded, because they were diagnosed with dementia. Moreover, almost 10 patients were also excluded because they required help of their primary caregiver to fill the questionnaire. Thus, a total of 420 geriatrics patients $(\geq 65$ Years old) were included for analysis.

\subsection{Data Collection}

A questionnaire has been structured about the Medication Knowledge Assessment (MKAQ). The questionnaires were filled out by study participants and their caregivers. The major components of MKAQ included investigating the knowledge medication in certain areas, such as number of medications, names, indications, directions of use and common side effects of each medication. The knowledge and answers about side effects were classified as "correct", "incorrect" or "I do not know". Baseline characteristics were recorded including the number of clinics followed outside the tertiary care center and the use of pain medications outside the prescriptions medication list. Polypharmacy has been classified as receiving five or more medications; whereas, the illiteracy was defined as the inability to write or read. Furthermore, the perception of elders concerning the education and knowledge of medication provided by HCPs has also been evaluated. After the questionnaires have been filled out, participant's satisfaction was obtained. No formal satisfaction survey was done; however, a simple question has been asked, whether they found this interview helpful or not regarding enhancing the understanding of their medications.

\subsection{Ethical Consideration}

The study has been approved by Institutional review Board at the center, and informed consent has also been obtained. The research has been carried out in compliance with the ethical rules for human experimentation, which are stated in the Declaration of Helsinki (Amdur \& Biddle, 1997).

\subsection{Data Analysis}

SPSS software has been used to conduct statistical analysis to analyze the results of the study. The computation of baseline characteristic data regarding the patients, such as mean age, gender, the number of medications used by patients, the percentage of patients using herbal or Over the Counter medication (OTC) were analyzed. The patients' knowledge of different aspects of the questionnaire was acquired through descriptive statistics. Moreover, the relationship between level of education and various aspects of knowledge have been evaluated through chi-square test. T-test has also been conducted for the measurement of the statistical relationship between a number of medications and various aspects of knowledge.

\section{Results}

Despite the increased age and multiple medical problems, a significant number of elders are still self-dependent in taking and managing their medications (47\%). It has been identified through outcomes that approximately $50 \%$ of elders were illiterate. Moreover, the use of OTC drugs has been observed among $20 \%$ of elder patients. Approximately, $6 \%$ of the patients used pain killers besides the prescribed medications; however, the usage of herbal medication has also been found among $8 \%$ of the patients. Table 1 has pointed out the details regarding the baseline characteristics of study participants. 
Table 1. Baseline Characteristics of Patients

\begin{tabular}{|c|c|c|c|}
\hline & & Number & Percentage \\
\hline \multirow[t]{2}{*}{ Gender } & Male & 235 & $56 \%$ \\
\hline & Female & 185 & $44 \%$ \\
\hline \multicolumn{2}{|l|}{ Mean age } & $7+/ 3$ & \\
\hline \multirow[t]{5}{*}{ Level of Education } & Illiterate (Unable to read or write) & 208 & $49.5 \%$ \\
\hline & Primary School & 86 & $20.5 \%$ \\
\hline & Intermediate & 82 & $19.5 \%$ \\
\hline & Secondary & 30 & $7,2 \%$ \\
\hline & University & 14 & $3.3 \%$ \\
\hline \multirow[t]{2}{*}{ Nationality } & Saudi & 413 & $98 \%$ \\
\hline & Non-Saudi & 7 & $2 \%$ \\
\hline \multirow[t]{3}{*}{ Social Status } & Married & 258 & $61 \%$ \\
\hline & Widowed & 153 & $36.4 \%$ \\
\hline & Unknown & 9 & $2.1 \%$ \\
\hline \multicolumn{2}{|l|}{ Follow in more than 1 Hospital } & 33 & $8 \%$ \\
\hline \multirow[t]{4}{*}{ Pain medications } & & 29 & $7 \%$ \\
\hline & & & Acetaminophen (23) \\
\hline & & & NSAIDS (3) \\
\hline & & & Unknown (3) \\
\hline \multicolumn{2}{|l|}{ Mean Number of Medications } & $7+/ 33$ & $47.4 \%$ \\
\hline \multirow[t]{3}{*}{ Who Gives the Medications } & Self & 199 & $47.4 \%$ \\
\hline & Family Member & 162 & $38.6 \%$ \\
\hline & Housemaid & 59 & $14 \%$ \\
\hline Herbs Use & & 36 & $8.6 \%$ \\
\hline OTC use & & 83 & $20 \%$ \\
\hline
\end{tabular}

\subsection{Knowledge of Elders about Medications}

With respect to self-medications, it has been observed that elders were least aware regarding the names of their medications. A percentage of merely $3 \%$ to $18 \%$ of elderly patients have appropriate knowledge about the medications. Almost $17 \%$ of elderly patients have correctly identified the directions of using their medications; whereas, just less than $10 \%$ have awareness about side effects of their medications. The elders were most knowledgeable about where to keep their medications (73\%), and about the next refill date (82\%), which have been demonstrated in Table 2. 
Table 2. Relations of studied Parameters with Level of Education and Polypharmacy

\begin{tabular}{|c|c|c|c|}
\hline Studied Parameters & $\begin{array}{l}\text { Percentage of Knowledge } \\
\text { Results }\end{array}$ & $\begin{array}{l}\text { Relationship with Level of } \\
\text { Education (Chi-Square) }\end{array}$ & $\begin{array}{l}\text { Relationship with Number of } \\
\text { Medications (T-Test) }\end{array}$ \\
\hline Names of Medication & $3 \%$ & $\mathrm{P}=0.001$ & $\mathrm{P}=0.821(\mathrm{NS})$ \\
\hline Indications & $18 \%$ & $\mathrm{P}=0.005$ & $\mathrm{P}=0.001$ \\
\hline Directions of Use & $17 \%$ & $\mathrm{P}=0.001$ & $\mathrm{P}=0.004$ \\
\hline \multirow[t]{3}{*}{ Side Effects } & I don't know $(65 \%)$ & & \\
\hline & Incorrect (26\%) & $\mathrm{P}=0.032$ & $\mathrm{P}=0.55(\mathrm{NS})$ \\
\hline & Correct (9\%) & & \\
\hline Next Refill & $73 \%$ & $\mathrm{P}=0.43(\mathrm{NS})$ & $\mathrm{P}=0.79(\mathrm{NS})$ \\
\hline Storage & $82 \%$ & $\mathrm{P}=0.75(\mathrm{NS})$ & $\mathrm{P}=0.13$ (NS) \\
\hline
\end{tabular}

Note. $\mathrm{NS}=$ Non-Significant results. P-value less than $0.05=$ Significant.

It is evaluated through outcomes, that age factor has no relationship with Medication Knowledge; however, male patients were found to have more knowledge about indications $(\mathrm{P}=0.03)$ and direction of use $(\mathrm{P}=0.04)$. The knowledge about the name of medication, its indications, directions of use, and side effects have been observed to be associated with the education level of elderly patients. On the other hand, a number of medications have a significant association with the directions of use and indications of medication. Concerning the next refill and storage of medications, it has been observed that elder patients scored best within these areas. Therefore, it can be said that this knowledge cannot be influenced by the level of education and number of medications.

\subsection{Perceived Knowledge provided by HCPs about Medications}

It is noteworthy that majority of the elders (almost three quarters) expressed that the information provided by HCPs about their medications was inadequate. It has been assessed that majority of the elders found this interview useful for enhancing the knowledge regarding their medications (Table 3).

Table 3. Knowledge perceived by health care professionals

\begin{tabular}{lll}
\hline Degree of clearance & Number/Percentage & Comments \\
\hline Clear and Adequate & $113.4(27 \%)$ & $\begin{array}{l}\text { Knowledge perceived by Healthcare } \\
\text { professionals was clear. }\end{array}$ \\
\hline To Certain Extent & $205.8(49 \%)$ & $\begin{array}{l}49 \% \text { of the participants had perceived the } \\
\text { knowledge to some extent }\end{array}$ \\
\hline Not at All & $100.8(24 \%)$ & $\begin{array}{l}24 \% \text { of the participants had not perceived } \\
\text { knowledge at all. }\end{array}$ \\
\hline
\end{tabular}

\section{Discussion}

The provision of instructions as well as appropriate information encompassed the labeling of medications to assure an efficient and safe usage of medications among patients. In actual practice, the labeling of medication has usually been observed inconsistent and difficult for the patients to understand. Due to this unclear information, the chances of medication errors can be enhanced, which might result in loss of life as well (Alkhani, et al. 2013). It is the primary responsibility of health regulations that the information contained in medication pamphlets including their names, should be written in the native language, besides the language of origin. The prescriptions dispensed by ambulatory care pharmacies should have instructions for use in the native language. Despite that, there seems to be a major gap in Medication Knowledge among the elders. Past studies have indicated that illiteracy is one of the major aspects. Therefore, Medication Knowledge is strongly related to adherence as well as optimal outcomes for geriatric population (Franks et al., 2005; Okuyan et al., 2013). From the outcomes, it has been examined that illiteracy was the strongest factor, which seems to be associated with all aspects of Medication Knowledge and may be the main explanation for this concern. The literacy rates were observed to vary among populations and illiteracy in general and limited health literacy was shown to be associated with increased mortality among elderly 
patients (Sudore, et al. 2006; Baker, et al. 2007). Hence, it has evaluated the importance of literacy, which serves as a significant means to overcome certain communities for the improvement of medication knowledge in elderly populations.

Earlier conducted studies reflected some conflicting outcomes in contrast with the results of this study, regarding the assessment of knowledge. Some studies have shown good knowledge with regards to the name, indications, and directions of use (Barat et al., 2001; Chan, et al. 2013). The poor knowledge regarding the side effects of medication has been observed to be consistent with studies conducted earlier (Barat et al., 2001; Modig, et al. 2009). Furthermore, it has been evaluated that there is an inverse association between adherence and poor knowledge (Okuyan et al., 2013; Barat et al., 2001).

Generally, Polypharmacy refers to the group of medications, which are likely to be taken by an individual. Among the elderly patients, polypharmacy has been observed as a common issue, with increasing requirements of medications in accordance with the morbidities associated with age (Rambhade, et al. 2012; Kim, et al. 2014). Moreover, it has also been classified as an import factor that affected many aspects of medication knowledge. With respect to this study, polypharmacy has been considered as it is associated with the knowledge of names, indications, and directions of use. It has been evaluated by Pasina et al. (2014) that there is a poor association among adherence and polypharmacy. Further attempts should be made to optimize polypharmacy in elderly population, as supported by other studies (Eckardt, et al. 2014; Loffler, et al. 2014).

It has been evaluated that HCPs usually provide adequate information with respect to their medications. This is the reason due to which elderly patients have been observed to gain reasonable scores about the knowledge of next refills as well as the storage of their medications. The latter observation supported that knowledge can be improved as the elders grasped this aspect of knowledge more clearly. The outcomes of the study highlighted the need for research to enhance the ability of HCPs and to educate the elders regarding their medications. Studies have advocated that providing more time and availability to answer questions can improve knowledge in elders (Modig, et al. 2012). With visual, auditory, and educational background limitations, the best modality of education needs to be individualized. As half of the elders depend on caregivers for their medications, the caregivers should also be targeted to further enhance the knowledge of medications. The same recommendation has been supported by the work of Mannucci et al. (2014). Prospective comparative studies are required for identification of the best education aids for elders, as well as for their caregivers to enhance knowledge. A proposed knowledge enhancement regarding the medication among the elders and their caregivers can be observed from figure 1 . 


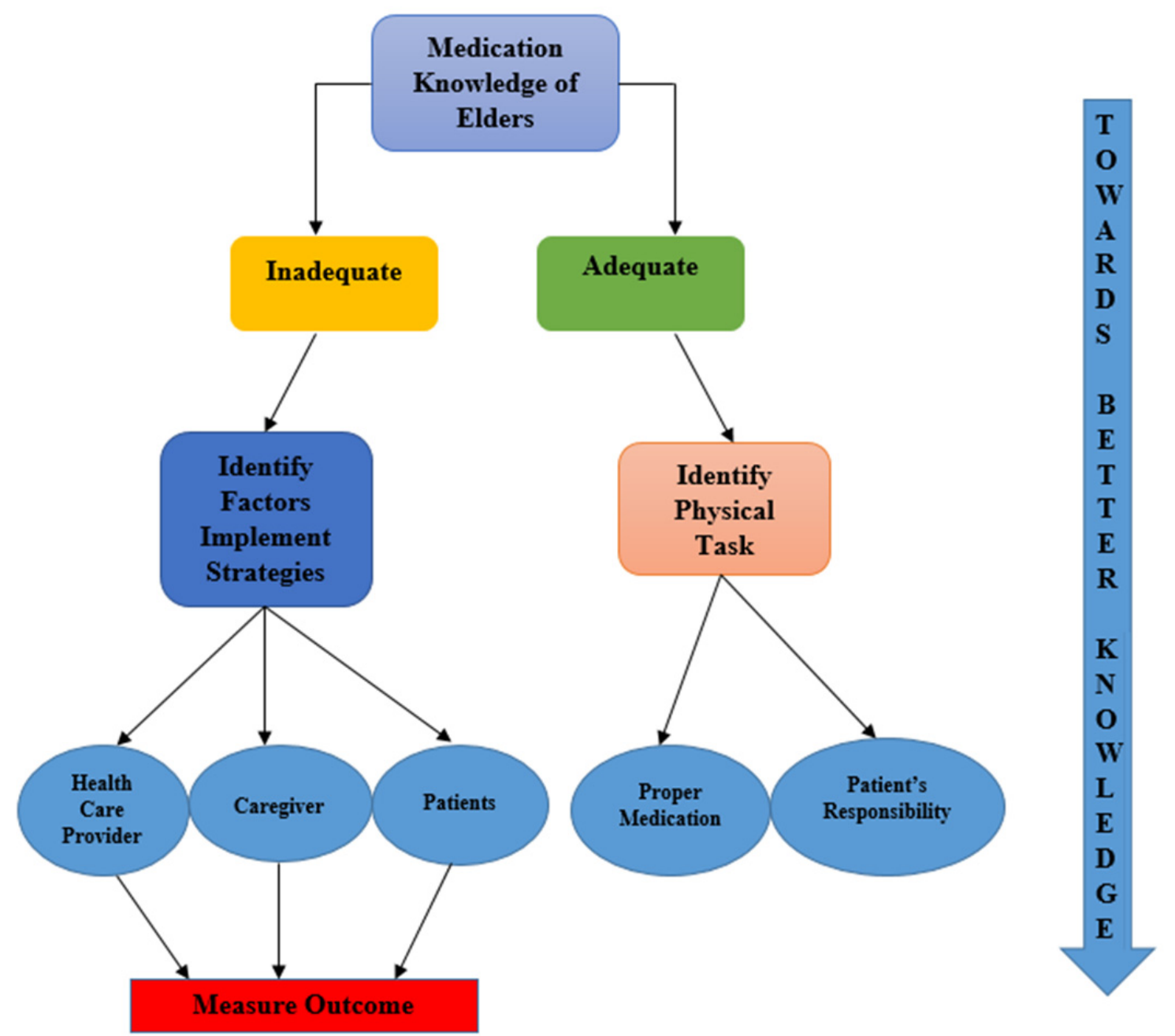

Figure 1. Proposed Schema for Elders about their Medication

In the population, the elders were willing to participate in clinical studies. Reviewing medication knowledge was welcomed and perceived as having a positive impact on medication knowledge. Regular medication reviews in elders exploring knowledge and understanding of their medications have also been encouraged.

The HCPs are needed to have awareness about medications among elder patients. The elder patients seemed to be least knowledgeable about the side effects. Factors contributing to poor knowledge, including illiteracy and polypharmacy, are observed to be prevalent aspects; however, not appropriate always. It has been considered by most of the elders that insufficient knowledge has been provided usually by healthcare professionals on the medications. Although, reaching knowledge perfection may not be a practical goal with multiple limitations; however, there is certainly an enormous opportunity for improvement. HCP needs to rethink and evaluate the currently implemented practices to provide an appropriate education to the elders about their medications. Limitations that affects on acquiring knowledge should be identified, and the interventions should be individualized and tailored. Many elders are more dependent on caregivers, and improving caregivers' knowledge will ultimately improve medication knowledge.

Prospective studies are needed to identify best tools, which would be suitable for the elders and their caregivers for knowledge enhancement. The impact of these interventions in improving knowledge, safety, adherence and overall outcomes are required to be measured. The elders showed willingness to participate in trials appropriately. Regular medication reviews among elders should be encouraged that will improve the overall safety of medications.

\section{Acknowledgements}

The authors are very thankful to all elder patients, who agreed to participate in order to share their perspectives to contribute in/for the purpose of this research. 


\section{Competing Interests Statement}

The authors declare that there are no competing or potential conflicts of interest.

\section{References}

Alkhani, S., Ahmed, Y., Bin-Sabbar, N., Almogirah, H., Alturki, A., Albanyan, H., \& Vaida, A. J. (2013). Current practices for labeling medications in hospitals in Riyadh, Saudi Arabia. Saudi Pharmaceutical Journal, 21(4), 345-349. https://doi.org/10.1016/j.jsps.2012.12.002

Amdur, R. J., \& Biddle, C. (1997). Institutional review board approval and publication of human research results. Jama, 277(11), 909-914. https://doi.org/10.1001/jama.277.11.909

Baker, D. W., Wolf, M. S., Feinglass, J., Thompson, J. A., Gazmararian, J. A., \& Huang, J. (2007). Health literacy and mortality among elderly persons. Archives of Internal Medicine, 167(14), 1503-1509. https://doi.org/10.1001/archinte.167.14.1503

Barat, I., Andreasen, F., \& Damsgaard, E. M. S. (2001). Drug therapy in the elderly: what doctors believe and patients actually do. British journal of clinical pharmacology, 51(6), 615-622. https://doi.org/10.1046/j.0306-5251.2001.01401.x

Boffetta, P., Bobak, M., Borsch-Supan, A., Brenner, H., Eriksson, S., Grodstein, F., \& Kee, F. (2014). The Consortium on Health and Ageing: Network of Cohorts in Europe and the United States (CHANCES) project - design, population and data harmonization of a large-scale, international study. European journal of epidemiology, 29(12), 929-936. https://doi.org/10.1007/s10654-014-9977-1

Chan, F. W. K., Wong, F. Y. Y., So, W. Y., Kung, K., \& Wong, C. K. M. (2013). How much do elders with chronic conditions know about their medications?. BMC geriatrics, $13(1), \quad 59$. https://doi.org/10.1186/1471-2318-13-59

Eckardt, R., Steinhagen-Thiessen, E., Kampfe, S., \& Buchmann, N. (2014). Polypharmacy and drug prescription in the elderly. Strategies for optimization. Zeitschrift fur Gerontologie und Geriatrie, 47(4), $293-301$. https://doi.org/10.1007/s00391-013-0562-0

Franks, T. J., Burton, D. L., \& Simpson, M. D. (2005). Patient medication knowledge and adherence to asthma pharmacotherapy: a pilot study in rural Australia. Therapeutics and clinical risk management, 1(1), 33. https://doi.org/10.2147/tcrm.1.1.33.53598

Kim, H. A., Shin, J. Y., Kim, M. H., \& Park, B. J. (2014). Prevalence and predictors of polypharmacy among Korean elderly. PloS one, 9(6), e98043. https://doi.org/10.1371/journal.pone.0098043

Loffler, C., Drewelow, E., Paschka, S. D., Frankenstein, M., Eger, J., Jatsch, L., \& Schröder, H. (2014). Optimizing polypharmacy among elderly hospital patients with chronic diseases - study protocol of the cluster randomized controlled POLITE-RCT trial. Implementation Science, 9(1), 151. https://doi.org/10.1186/s13012-014-0151-7

Maher, R. L., Hanlon, J., \& Hajjar, E. R. (2014). Clinical consequences of polypharmacy in elderly. Expert opinion on drug safety, 13(1), 57-65. https://doi.org/10.1517/14740338.2013.827660

Mannucci, P. M., Nobili, A., \& REPOSI Investigators. (2014). Multimorbidity and polypharmacy in the elderly: lessons from REPOSI. Internal and emergency medicine, 9(7), 723-734. https://doi.org/10.1007/s11739-014-1124-1

Modig, S., Kristensson, J., Ekwall, A. K., Hallberg, I. R., \& Midlov, P. (2009). Frail elderly patients in primary care - their medication knowledgee and beliefs about prescribed medicines. European journal of clinical pharmacology, 65(2), 151-155. https://doi.org/10.1007/s00228-008-0581-8

Modig, S., Kristensson, J., Troein, M., Brorsson, A., \& Midlov, P. (2012). Frail elderly patients' experiences of information on medication. A qualitative study. BMC geriatrics, $12(1), \quad 46$. https://doi.org/10.1186/1471-2318-12-46

Okuyan, B., Sancar, M., \& Izzettin, F. V. (2013). Assessment of medication knowledge and adherence among patients under oral chronic medication treatment in community pharmacy settings. Pharmacoepidemiology and drug safety, 22(2), 209-214. https://doi.org/10.1002/pds.3275

Pasina, L., Brucato, A. L., Falcone, C., Cucchi, E., Bresciani, A., Sottocorno, M., \& Nobili, A. (2014). Medication non-adherence among elderly patients newly discharged and receiving polypharmacy. Drugs \& aging, 31(4), 283-289. https://doi.org/10.1007/s40266-014-0163-7 
Rambhade, S., Chakarborty, A., Shrivastava, A., Patil, U. K., \& Rambhade, A. (2012). A survey on polypharmacy and use of inappropriate medications. Toxicology international, $19(1), 68$. https://doi.org/10.4103/0971-6580.94506

Sudore, R. L., Yaffe, K., Satterfield, S., Harris, T. B., Mehta, K. M., Simonsick, E. M., \& Ayonayon, H. N. (2006). Limited literacy and mortality in the elderly: the health, aging, and body composition study. Journal of general internal medicine, 21(8), 806-812. https://doi.org/10.1111/j.1525-1497.2006.00539.x

Swe, L. A., Nyo, K. K., \& Rashid, A. K. (2010). Risk behaviours among HIV positive injecting drug users in Myanmar: a case control study. Harm reduction journal, 7(1), 12. https://doi.org/10.1186/1477-7517-7-12

Wayne, R. V., \& Johnsrude, I. S. (2015). A review of causal mechanisms underlying the link between age-related hearing loss and cognitive decline. Ageing research reviews, 23, 154-166. https://doi.org/10.1016/j.arr.2015.06.002

Wiener, J. M., \& Tilly, J. (2002). Population ageing in the United States of America: implications for public programmes. International journal of epidemiology, 31(4), 776-781. https://doi.org/10.1093/ije/31.4.776

Wu, J. R., Moser, D. K., Chung, M. L., \& Lennie, T. A. (2008). Predictors of medication adherence using a multidimensional adherence model in patients with heart failure. Journal of cardiac failure, 14(7), 603-614. https://doi.org/10.1016/j.cardfail.2008.02.011

\section{Copyrights}

Copyright for this article is retained by the author(s), with first publication rights granted to the journal.

This is an open-access article distributed under the terms and conditions of the Creative Commons Attribution license (http://creativecommons.org/licenses/by/4.0/). 